ATTHULAB:

Islamic Religion Teaching $\mathcal{E}$ Learning Journal

Volume 5 Nomor 1 Tahun 2020

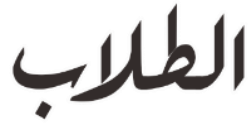

http://journal.uinsgd.ac.id./index.php/atthulab/

\title{
Nilai-nilai Budaya Sekolah dalam Pembinaan Aktivitas Keagamaan Siswa
}

\author{
Muhammad Iqbal Arrosyad1), Siti Nur Oktaviani2), Harsela Eftia3), \\ Nadia Karisma ${ }^{4)}$ dan Bella Meliyana ${ }^{5)}$ \\ Sekolah Tinggi Keguruan dan Ilmu Pendidikan Muhammadiyah Bangka Belitung \\ Jl. KH. A Dahlan, Mangkol, Kabupaten Bangka Tengah, \\ Kepulauan Bangka Belitung, Indonesia \\ 1)Email: muhammad.iqbalarrosyad@stkipmbb.ac.id \\ 2)Email: Oktaviaaa17@gmail.com \\ 3)Email: selajudith407@gmail.com \\ 4)Email: zonetnadia@gmail.com \\ 5)Email: Bellameliyana06@gmail.com
}

\begin{abstract}
The purpose of the study is to explain the school's cultural values in fostering religious activities. This research took place in public elementary school 5 Mendo Barat. The research method used is descriptive qualitative methods. Data collection techniques used are structured and unstructured interviews, observation, and documentation to obtain relevant data. The subjects of this study were the principal, teacher, and students. The results of this study include: 1) Inculcation of school cultural values such as shame culture, religious culture, responsibility literacy culture, and culture of respect for people who are young or older.2) Implementation of fostering religious activities in public elementary school 5 Mendo Barat. 3) Advantages and disadvantages of carrying out religious activities public elementary school 5 Mendo Barat is like the cultivation of religious knowledge in children from an early age is very good. This study found that school cultural values in the fostering of religious activities have been instilled early on by every teacher to students well where they have been taught religious habituation and the inculcation of school cultural values to from learners with character and noble character.
\end{abstract}

Keywords:

school cultural values; religious activities

Abstrak: Tujuan penelitianmenjelaskan tentang nilai-nilai budaya sekolah dalam pembinaan aktivitas keagamaan, penelitian ini mengambil lokasi di SD Negeri 5 Mendo Barat. Metode penelitian yang digunakan yakni metode deskriptif kualitatif. Teknik pengumpulan data yang digunakan yakni wawancara terstruktur dan tidak terstruktur, observasi dan dokumentasi agar memperoleh data yang relevan. subjek penelitian ini adalah kepala sekolah, guru, dan siswa. Hasil penelitian ini diantaranya: 1) Penanaman nilai-nilai budaya sekolah seperti budaya malu, budaya religious, tanggung jawab, budaya literasi, dan budaya menghormati orang yang muda maupun yang lebih tua. 2) Pelaksanaan Pembinaan aktivitas keagamaan di SD Negeri 5 Mendo Barat 3) Kelebihan dan kekurangan aktivitas keagamaan SD Negeri 5 Mendo Barat yakni seperti penanaman ilmu agama kepada anak sejak usia dini sangat baik. Penelitian ini menemukan bahwa nilai-nilai budaya sekolah dalam pembinaan aktivitas keagamaan telah di tanamkan sejak dini oleh setiap guru terhadap peserta didik dengan baik dimana telah di ajarkan pembiasaan keagamaan dan penanaman nilai budaya sekolah sehingga dapat membentuk peserta didik yang berkarakter dan berakhlak mulia.

Kata Kunci:

Nilai-nilai budaya sekolah; aktivitas keagamaan

DOI: http://dx.doi.org/10.15575/ath.v5i1.7697

Received: 02, 2020. Accepted: 04, 2020. Published: 04, 2020. 


\section{PENDAHULUAN}

Budaya sekolah merupakan sesuatu yang dibangun dari hasil pertemuan (Muhaimin, 2002) antara nilai-nilai (values) yang dianut oleh guru-guru dan para karyawan yang ada dalam sekolah. Akan tetapi menurut (Parman Komarudin \& Muhammad Rifqi Hidayat, 2018) tanpa budaya sekolah yang bagus, akan sulit melakukan pendidikan karakter bagi anak-anak didik. Jika, budaya sekolah sudah mapan, siapun yang masuk dan bergabung disekolah itu hampir secara otomatis akan mengikuti tradisi yang sudah ada.

Budaya sekolah selalu dibangun pikiran-pikiran individu yang ada didalamnya. Nilai-nilai mempengaruhi keunggulan sekolah, (Muhaimin; 2011). Karena nilai-nilai mempengaruhi cara bertindak seseorang. Apabila nilai-nilai diimplementasikan oleh keseluruhan orang-orang diorganisasi, maka tentu akan mempengaruhi perilaku organisasi tersebut, termasuk produktivitas organisasi. Sekolah merupakan wadah dalam pembinaan aktivitas keagamaan siswa dan merupakan lembaga tempat berjalannya kegiatan pendidikan yang harus mempunyai misi dalam menciptakan budaya sekolah yang menantang dan menyenangkan, adil, kreatif, inovatif, terintergrasi, dan menghasilkan lulusan yang berkualitas tinggi dalam perkembangan intelektualnya dan mempunyai karakter takwa, jujur, kreatif, maupun menjadi teladan, bekerjakeras, toleran dan cakap dalam memimpin serta menjawab tantangan akan kebutuhan pengembangan sumberdaya manusia yang dapat berperan dalam perkembangan iptek dan berlandaskan imtak (Siregar, 2017). Dalam sebuah literatur dijelaskan, apabila manusia berpegang teguh terhadap agama Islam, maka akan memperoleh keuntungan yang sangat banyak. Seperti kehidupan manusia akan menjadi terarah, mendapatkan ketenangan dalam hidup, meningkatkan keyakinan dalam beragama, menghindarkan diri dari perilaku buruk dan meningkatkan toleransi (Haryanto, 2013).

Nilai-nilai religius berhubugan erat dengan karakter siswa pada dasarnya, karena manusia terlahir dengan sifat kearifan (fitrah) yaitu sifat cenderung kepada kebenaran. (Man et al., 2018) menjelaskan manusia terlahir dilengkapi dengan sifat kearifan (fitrah) yaitu sifat untuk cenderung kepada kebenaran. Sifat yang dimaksud adalah sifat bawaab semua manusia tanpa terkecuali. Hal tersebut menunjukkan bahwa semua manusia berpotensi menjadi baik karena manusia sudah dilengkapi dengan sifat bawaan yang baik (Al-Warisy, 2012: 106).

Mutu sekolah dapat dilihat dari budaya yang hidup dan dikembangkan warga sekolah. Budaya sekolah adalah sekumpulan nilai yang melandasi perilaku, tradisi, kebiasaan keseharian, dan symbol-simbol yang dipraktekkan oleh kepala sekolah, guru, petugas administrasi, siswa dan masyarakat sekitar sekolah. (Maryamah, 2016). Dengan demikian mutu sekolah akan dapat dilihat dari bagaimana perilaku dan juga nilai-nilai yang diterapkan didalam sekolah dengan dorongan langsung oleh kepala sekolah, guru, petugas administrasi, siswa dan masyarakat sekitar sekolah.

Keberagaman nilai-nilai budaya keagamaan disekolah tergantung pada apa tujuan yang ingin dicapai, karena hasil penerapan dan pelaksanaan nilainilai budaya akan menjadi dasar dari perilaku siswa di sekolah maupun di luar 
sekolah seperti dirumah. Hal tersebut juga dikatakan (Izzet et al., 2017) sebagai upaya untuk meningkatkan relevansi dan kualitas karakter siswa serta mrngimbangi kebutuhan peserta didik terhadap pemahaman agama, pemerintas mengambil kebijakan penerapan kurikulum Pendidikan agama yang ditempatkan pada kurikulum nasional sebagai muatan wajib untuk tingkat Sekolah Dasar (SD) maupun Sekolah Menengah atau yang sederajat. Dengan demikian nilai-nilai budaya telah ditetapkan dari pemerintah melalui Pendidikan agama yang ditempatkan pada kurikulum dan nilai budaya tersebut dapat menunjang siswa dalam segi relevansi dan karakternya.

Penelitian ini didasari dengan rumusan masalah diantaranya adalah Bagaimana nilai-nilai budaya sekolah di SD Negeri 5 Mendo Barat, Bagaimana penerapan pelaksanaan pembinaan aktivitas keagamaan di SD Negeri 5 Mendo Barat dan Kelebihan dan kekurangan pembinaan aktivitas keagamaan siswa di SD Negeri 5 Mendo Barat. Dan tujuan dari penelitian ini adalah untuk mengetahui nilai-nilai budaya sekolah yang ada di SD Negeri 5 Mendo Barat, mengamati pelaksanaan pembinaan aktivitas keagamaan di SD Negeri 5 Mendo Barat, dan Mengetahui kelebihan dan kekurangan pembinaan aktivitas keagamaan di SD Negeri 5 Mendo Barat.

Penelitian ini merupakan penelitian yang dikaji dengan dasar penelitian lain, oleh sebab itu ada beberapa penelitian yang relevan dengan penelitian ini diantaranya penelitian dari (Fitri, 2012) kesamaan dengan penelitian ini yakni pembahasan berhubungan dengan nilai budaya sekolah, selain itu juga etika yang baik dapat mendukung keberhasilan program Pendidikan karakter, pementukkan karakter dalam Pendidikan formal tidak dapat terlepas dari keterlibatan kepala sekolah, guru, dan orangtua siswa yang memiliki andil sangat besar dalam menentukan keberhasilanya.

Peneliti lain (Tinggi et al., 2015) memiliki kesamaan bahwa kultur sekolah merupakan strategi untuk membumikan deradikalisasi agama di sekolah, maksudnya siswa dapat mendalami dan meyakini ajaran agamanya sendiri, berkomitmen mentranformasikan ajaran agamanya secara baik dalam kehidupan pribadi maupun social bermasyrakat, dan memberikan teladan secara konkret tidak terjebak menggunakan kekerasan dan anarkisme dalam mewujudkan keinginan.

Nilai-nilai keagamaan juga dibahas oleh (Klaten, 2019) sifat-sifat karakter siswa, kesehatan, hobi, keadan rumah, masyarakat, dan motivasi memiliki kendala dalam penerapannya, karena setiap siswa memiliki potensinya sendirisendiri dan kemampuan yang berbeda. Usaha yang dilakukan guru yakni guru tidak membeda-bedakan antara satu dengan yang lainnya, bekerjasama dengan guru yang lainnya, memberi tugas supaya diselesaikan dirumah Bersama orang tua, memberi motivasi kepada siswa, guru juga harus meningkatkan potensi mengajarnya, dan guru tidak boleh putus asa.

Pembinaan nilai-nilai agama yang diterapkan di SD N 5 Mendo Barat merupakan nilai-nilai budaya yang sudah ada sejak lama, dengan demikian nilai-nilai tersebut akan bertahan lama dan dapat menjadi dasar karakter yang baik oleh siswa. Penerapan yang dilakukan tersebut membuahkan hasil yang 
baik, sehingga ada berbagai pendorong khusus dalam pelaksanaannya. Pendorong atau penyongsong terlaksananya penerapan nilai-nilai budaya pada arahan keagamaan ini akan menjadi pemahasan khusus dalam penelitian ini. Dengan demikian aka nada luaran gagasan baru dari hasil penelitian ini. Luaran baru atau temuan yang ada akan dijabarkan secara jelas diakhir pembahasan.

\section{METODE PENELITIAN}

Jenis penelitian ini adalah penelitian deskriptif-kualitatif, menurut Sumanto yang dikutif oleh (Priatna, 2007) metode deskriptif adalah penelitian yang diupayakan untuk mengamati permasalahan secara sistematis dan akurat mengenai fakta-fakta dan sifat-sifat objek tertentu. Teknik pengumpulan data yang digunakan adalah dokumentasi dan wawancara tersetruktur dan wawancara tidak tersetruktur yang dirancang untuk menggali informasi tentang nilai-nilai budaya sekolah dalam pembinaan aktivitas keagamaan di SD Negeri 5 Mendo Barat. Penelitian ini dilaksanakan di SD Negeri 5 Mendo Barat, Waktu penelitian dilaksanakan selama 10 hari, yaitu di mulai dari tanggal 22 Januari 2020 - 3 Februari 2020.

Subjek penelitian ini adalah Kepala sekolah, guru agama islam, dan siswa di SD N 5 Mendo Barat. Objek penelitian adalah nilai-nilai budaya sekolah dalam pembinaan aktivitas keagamaan.

\section{HASIL PENELITIAN DAN PEMBAHASAN}

\section{Nilai-nilai budaya sekolah yang di bina di SD N 5 Mendo Barat}

Dalam penelitian ini diperoleh hasil yang akan diuraikan tentang posisi temuan penelitian terhadap teori-teori penafsiran dan temuan yang diungkapkan dilapangan, adapun hal yang dapat dipaparkan yang berkaitan dengan fokus penelitian adalah Nilai-nilai Budaya Sekolah Dalam Pembinaan Aktivitas Keagamaan Siswa SD 5 Mendo Barat.

Dalam kegiatan observasi yang kami lakukan selama 10 hari di SD 5 Mendo Barat, nilai-nilai budaya sekolah dalam pembinaan aktivitas keagamaan siswa SD 5 Mendo Barat yang berjalan dengan baik.

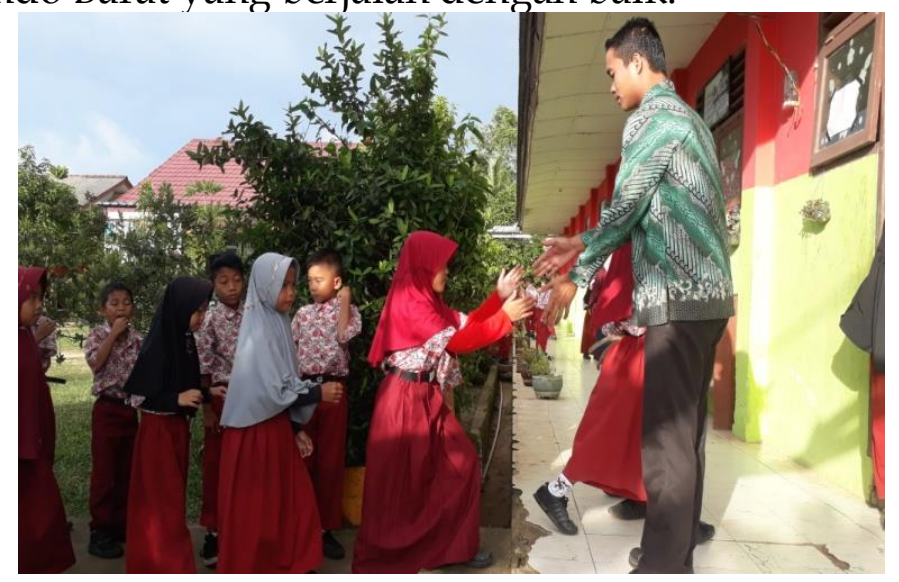

Gambar 1. Budaya 3S, Senyum, sapa dan salam yang harus dilakukan peserta didik Di SD N 5 Mendo Barat. 
Setiap waktu anak-anak di SD Negeri 5 Mendo Barat melakukan kegiatan 3S, yang mana kegiatan 3S termasuk dalam ajaran agama islam. Sesama muslimin kita harus memberikan salam, menyapa dan memberikan senyuman yang merupakan salah satu ibadah paling mudah dilakukan setiap orang. Misalnya jika siswa berpapasan dengan guru yang bukan masuk kekelasnya ia wajib menyalam guru tersebut.

Dari hasil wawancara kami bersama guru di SD Negeri 5 Mendo Barat yakni, Untuk nilai-nilai budaya sekolah, sekolah menerapkan dan menanamkan pada anak budaya malu, budaya religius, tanggung jawab, budaya literasi, budaya saling menghormati baik yang muda maupun yang tua. Budaya malu misalnya malu berbohong, malu datang terlambat disekolah, malu tidak mengerjakan tugas, malu mencuri, malu mencontek.

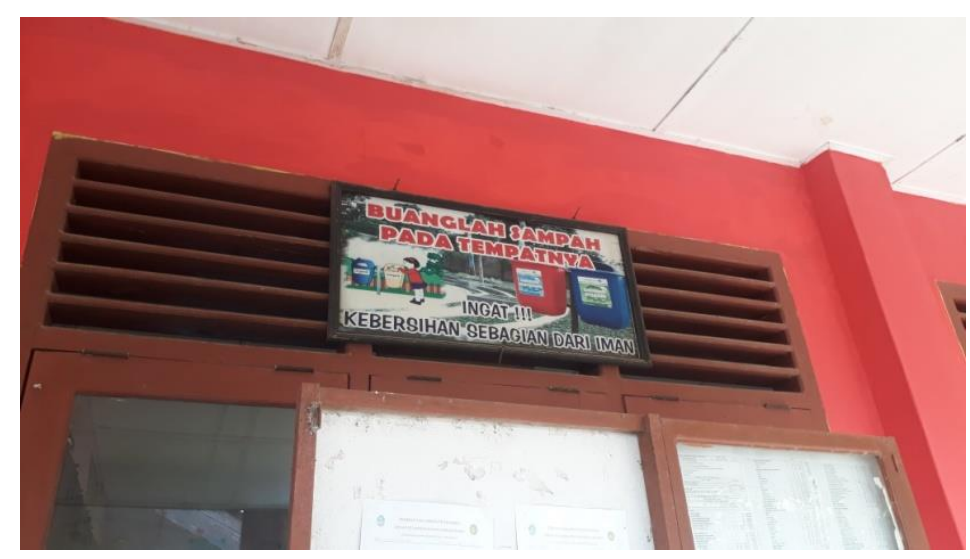

\section{Gambar 2. Budaya perduli terhadap lingkungan yang di tanamkan kepada peserta didik sejak dini}

Setiap pagi guru-guru dan anak-anak melakukan kegiatan kerja bakti dimana dalam hal tersebut siswa diajarkan untuk membersihkan lingkungan, dimana dalam agama juga diajarkan untuk menjaga kebersihan "kebersian sebagian dari Iman". Selain itu juga siswa diajarkan untuk selalu membuang sampah pada tempatnya saat membeli jajanan disekolah.

Sebelum kegiatan pembelajaran dimulai dikelas selalu diawali dengan baris berbaris didepan kelas, kemudian siswa maju perbarisan sambil bersalaman dengan guru yang mengajari pada jam tersebut dan masuk kedalam kelas dengan rapi. Kemudian Guru masuk ke dalam kelas sambil mengucapkan salam "assalamu'alaikum" dan siswa serentak tanpa aba-aba menjawab salam tersebut "wa' alaikumussalam".

Pembacaan doa yang di instruksikan guru untuk memulai proses pembelajaran yang dipimpin ketua kelas. Dari hasil pengamatan kami dikelas, saat siswa kelas 3 SD N 5 Mendo Barat melakukan kesalahan dalam pembacaan doa, saat setelah selesai pembacaan doa, bapak Darwin (guru Matematika) langsung mengkoreksi kesalahan tersebut, dan ia mencontohkan bacaan yang benar dan siswa disuruh melafadzkan kembali bacaan yang telah diucapkan guru tersebut. Setelah itu kami wawancarai beliau mengapa melakukan itu, 
beliau mengatakan bahwa hal tersebut penting dilakukan, dimana siswa-siswi masih berusia muda, jadi sejak dini kita ajarkan yang baik dan benar agar kedepannya mereka sudah fasih dalam melafadzkan bacaan tersebut. Rangkaian selanjutnya di SD Negeri 5 Mendo Barat, setelah pembacaan doa anak-anak membacakan sholawat. Ini merupakan salah satu kebijakan sekolah.

Budaya sekolah adalah sekumpulan nilai yang melandasi perilaku, tradisi, kebiasaan, keseharian, dan simbol-simbol yang dipraktikan oleh kepala sekolah, guru, peserta didik, dan kariawan sekolah (Sukardi, 2016). Dan tujuan dari penelitian ini adalah untuk mengetahui nilai-nilai budaya sekolah yang ada di SD Negeri 5 Mendo Barat, mengamati pelaksanaan pembinaan aktivitas keagamaan di SD Negeri 5 Mendo Barat, dan Mengetahui kelebihan dan kekurangan pembinaan aktivitas keagamaan di SD Negeri 5 Mendo Barat.

Nilai-nilai dalam budaya sekolah mencakup: kebiasaan hidup, etika, kejujuran, kasih sayang, mencintai belajar, bertanggung jawab, menghormati hukum dan peraturan, menghormati hak orang lain, mencintai pekerjaan, suka menabung, suka bekerja keras, tepat waktu (Maryamah, 2016).

Dari penelitian yang telah dilakukan adalah kebiasaan hidup yang bersih, kebiasaan ini sangat islami. Kebersihan sebagian dari pada iman, dan terdapat nilai-nilai religius dan nilai-nilai medis yang dapat dipetik oleh siswa dari kebiasaan ini. Ucapan dan tingkah laku yang baik dilakukan oleh siswa dari hati yang bersih. Etika atau akhlak mulia adalah tata aturan untuk bisa hidup bersama orang lain oleh karena itu harus ditanamkan etika yang baik sejak dini.

Semua warga sekolah dilatih berbuat jujur mulai jujur kepada dirinya sendiri, jujur kepada tuhan, dan jujur kepada oranglain. Kejujuran dibangun di sekolah melalui berbagai kegiatan pembelajaran, agar menghasilkan peserta didik sekarang dan masa yang akan datang menjadi manusia yang jujur dan tidak korupsi (Hadziq, 2016).

Kasih sayang antara siswa dan guru. Mencintai belajar harus ditanamkan oleh setiap guru kepada peserta didik agar peserta didik dapat mengembangkan pemikiran bahwa peserta didik akan belajar lebih bermakna, belajar menemukan pengetahuan dan keterampilan baru. Bertanggung jawab, seluruh warga sekolah harus dapat melaksanakan kewajiban dengan baik. Menghormati hukum dan peraturan, sekolah sebagai lembaga pendidikan harus memupuk kesadaran menghormati hukum dan peraturan kepada seluruh warga sekolah untuk kebaikannya. Setiap siswa di SD N 5 Mendo Barat diajarkan untuk menghormati hak orang lain dengan tidak melihat perbedaan status social, ekonomi, agama, dan budaya. Tepat waktu, semua warga sekolah diwajibkan untuk melaksanakan semua kegiatan yang ada disekolah dengan tepat waktu seperti datang kesekolah dan pulang sesuai waktu yang telah ditetapkan.

Peserta didik siap menerima pengaruh apapun dari orang lain, maka persipan dan pembinaan akhlaknya haruslah dilakukan sedini mungkin (Busroli, 2019). Peran keluarga menjadi hal urgen dalam pendidikan akhlak, dimana tanggung jawab pendidikan terletak pada orang tua, ketika pendidikan di keluarga berjalan baik, maka pada tingkat pendidikan berikutnya seperti di sekolah akan menjadi lebih baik. 
Budaya sekolah dalam penelitian ini adalah keseluruhan nilai-nilai dan norma-norma yang dianut sekolah yang meliputi; visi, misi, dan tujuan sekolah, ethos belajar, integrasi, norma agama, norma hukum dan norma social (Siregar, 2017). Sekolah Dasar Negeri 5 Mendo Barat memiliki budaya sekolah yang baik, dan berkarakter sesuai dengan visi dan misi sekolah yakni Unggul dalam prestasi, inovatif, santun, berkarakter, berwawasan lingkungan serta penyelenggaraan pendidikan inklusi. Sedangkan misi Sekolah Dasar Negeri 5 Mendo Barat yaitu 1) Mengoptimalkan pelaksaan KBM dan kegiatan ekstrakurikuler guna meningkatkan prestasi akademik maupun nonakademik agar mampu bersaing kejenjang pendidikan yang lebih tinggi. 2) Memotivasi setiap peserta didik untuk mengembangkan bakat dan minat yang dimiliki siswa. 3) Menciptakan sekolah yang bernuansa religious serta lingkungan yang bersih,sejuk, indah dan nyaman. 4) Meningkatkan professional pendidik dan tenaga kependidikan secara berkelanjutan serta menjalin kerjasama dengan mitra instansi lain yang relevan.

\section{Pembinaan Aktivitas Keagamaan Di SD N 5 Mendo Barat}

Sekolah Dasar Negeri 5 Mendo Barat selalu membiasakan pembinaan aktifitas keagamaan yang sangat disiplin. Seperti melaksanakan sholat berjamaah, rohis, kultum, bersholawat bersama dan tausiyah setiap hari jum'at. Selain itu Proses belajar Di Sekolah Dasar Negeri 5 Mendo Barat tidak hanya terjadi pada anak saja namun terjadi pada guru, orang tua dan masyarakat yang terlibat dalam proses pembelajaran. Hal tersebut untuk menuntut agar mereka memahami dan melaksanakan kewajiban-kewajiban seorang muslim terhadap Allah dimanapun mereka berada. Peserta didik juga diajarkan dan diberi pemahaman untuk menutup aurat sejak dini, tanpa paksaan. Selain itu dapat dilihat bahwa penerapan pakian di SD Negeri 5 Mendo Barat tidak ada lagi anakanak yang menggunakan pakaian pendek dibawah lutut, semua anak memakai celana/rok panjang. Disamping itu, para guru laki-laki menggunakan peci dan guru perempuan berpakaian sopan sehingga dapat menjadi contoh bagi peserta didik.

Pendidikan akhlak atau yang lebih dikenal dengan karakter adalah serangkaian prinsip dasar moral dan keutamaan sikap serta watak atau tabiat yang harus dimiliki dan dijadikan kebiasaan oleh anak sejak masa pemula hingga menjadi mukallaf, yakni siap untuk memengarungi lautan kehidupan. Akhlak adalah sifat yang tertanam dalam jiwa manusia, yang dapat dinilai baik atau buruk dengan menggunakan ukuran ilmu pengetahuan dan norma agama (Jamaluddin, 2017). Peserta didik harus memiliki akhlak yang mulia sesuai dengan agama yang dianutnya, dalam hal ini peserta didik yang beragama Islam harus memiliki akhlak religius sesuai dengan agama Islam. Dengan tercapainya tujuan dari pendidikan tersebut, sudah dapat dipastikan setiap peserta didik memiliki nilai karakter religius yang baik dan berperilaku sesuai dengan ajaran agama (Rosad, 2017). Kegiatan keagamaan dilaksanakan untuk menanamkan nilai religious pada setiap peserta didik (Tarbiyah et al., n.d.). Nilai religius mencakup perilaku-perilaku yang tampak dalam diri seseorang yaitu tawadhu', hormat, dan sopan santun (Surur, 2018). 
Pelaksaaan Pembinaan Aktivitas Keagaamaan Siswa di SD Negeri 5 Mendo Barat cukup baik yakni kegiatan Rohis yang dilakukan setiap Jum'at pagi. Selain itu pembiasaan keagamaan yang lainnya yakni setiap guru dikelas, sebelum melakukan proses pembelajaran pembacaan doa dan sholawat, yang mana bila terjadi kekeliruan dalam pembacaan doa ataupun sholawat akan langsung dikoreksi guru.

Untuk kegiatan rohis sendiri dilakukan setiap pagi jum'at, dimana sebelum memulai kegiatan anak diminta untuk menyumbangkan uang secara sukarela, dimana uang tersebut akan digunakan untuk pembangunan Mushola untuk SD Negeri 5 Mendo Barat. Kegiatan rohis dipimpin oleh guru PAI, yang mana guru PAI akan memberikan ceramah atau tausiyah, terkadang juga guru PAI menjuk salah satu murid untuk maju kedepan untuk meberikan tausiyah, hal tersebut juga melatih keberanian anak untuk berbicara didepan orang banyak. Setelah itu seluruh siswa dan guru akan membacakan sholwat bersama.

Dalam kegiatan memperingati hari-hari besar keagamaan seperti Isra' Miraj Nabi Muhammad SAW, sekolah melakukan budaya nganggung bersama di sekolh, yang mana sekolah juga mengundang para wali murid untuk berpartisipasi dalam kegiatan tersebut. Seperti yang kita ketahui kegiatan Nganggung merupakan budaya turun temurun tradisi nenek moyang yang masih ada hingga sekarang yang dilakukan masyarakat Bangka Belitung. Dalam kegiatan nganggung ini terdapat nilai budaya, nilai sosial, yang mana selain melestarikan budaya setempat, budaya nganggung bersama ini mempererat tali silaturahmi kekeluargaan yang mana dalam agama kita juga diajarkan untuk bersilaturahmi dengan saudara semuslim/semuslimah.

Selain itu saat di bulan suci Ramadhan sekolah juga melakukan bukber (buka bersama) dengan warga sekolah, hal ini juga bertujuan dan melestarikan nilai budaya sekolah, serta mempererat tali silatuhrami antara warga sekolah. Nilai budaya sekolah lainnya yakni selain nganggung dan buka bersama, sekolah juga berpartisipasi dalam kegiatan pawai ta'aruf yang dilakukan untuk memperingati hari-hari besar keagamaan, dalam kegiatan pawai ta'aruf ini seluruh sekolah yang ada di kecamatan Mendo Barat berpartisipasi sambil mengajarkan ke siswa nilai budaya.

Hal lainnya yang dilakukan sekolah dalam nilai-nilai budaya sekolah dan pembinaan aktivitas keagamaan siswa di SD Negeri 5 Mendo Barat ini, dalam hari-hari besar keagamaan sekolah juga memanggil ustadz atau tokoh agama untuk memberikan tausiyah, jadi seluruh warga sekolah yang berpartisipasi terutama siswa tau akan esensi dari kegiatan tersebut.

Dalam pembinaan aktivitas keagamaan siswa di SD Negeri 5 Mendo Barat ini yang melakukannya bukan hanya guru PAI, tapi seluruh guru berkontribusi dan bekerja sama dalam melakukan pembinaan aktivitas keagamaan tersebut.

\section{Kelebihan dan Kekurangan Pembinaan Aktivitas Keagamaan Di SD 5 Mendo Barat}

Kelebihan dari pembinaan aktivitas keagamaan sangat baik dalam penanaman ilmu agama kepada anak-anak sejak usia dini, karena ilmu agama 
sangat penting untuk seluruh manusia. dimana seperti yang kita ketahui bahwa Globalisasi (pergaulan) yang ada saat ini sangat menyeramkan, sehingga diharapkan ketika anak sudah memilki basic atau pondasi agama yang kuat sejak dini inshaAllah kedepannya anak bisa menjadi pribadi yang baik. Penanaman moral dan karakter anak sangat terkendali. Akhlak anak kepada orang yang lebih tua ataupun sepantaran mereka juga terkendali. Contoh nyata anak selalu menerapkan 3S, yang ada kegiatan 3S merupakan salah satu anjuran yang ada didalam agama.

Kekurangan dapat dijabarkan dengan kendala yang ada pada beberapa siswa kurangnya perhatian dari keluarga atau limgkungan dirumah tentang agama. Jadi ini sebagai tantangan pendidik untuk mengajarkan anak-anak tidak hanya ilmu pengetahuan tapi ilmu agama juga. Dalam pembinaan aktivitas keagamaan siswa di SD Negeri 5 Mendo Barat ini yang menjadi kendala ialah waktu, dimana jam sekolah juga terbatas dan berbagi dengan mata pelajaran yang lainnya. Tapi dalam pembinaan aktivitas keagamaan siswa di SD Negeri 5 Mendo Barat ini guru dapat menyisipkan nilai-nilai budaya dan keagamaan dalam kehidupan sehari-hari. Untuk kelas 6 diberikan waktu yang sebanyakbanyaknya untuk melakukan kegiatan sholat berjama'ah dilakukan oleh kelas tinggi seperti kelas 6, dimana mereka pulang lebih lama dibanding adik-adik kelasnya, jadi mereka melakukan sholat berjama'ah di masjid belakang sekolah.

Shalat merupakan interpretasi dari keimanan seseorang. Orang yang benar-benar sudah melewati proses pendidikan akidah, mengimani Allah, hari akhir, kitab-kitab, dan para nabinya, pasti akan berimbas baik pada shalatnya. Shalat merupakan media yang bisa menghubungkan hamba dengan penciptanya. Oleh karenanya, manusia harus benar-benar menggunakan akhlak dalam berinteraksi dan berkomunikasi dengan Tuhannya (Anwar \& Nuryana, 2019). Orang yang senantiasa melaksanakan shalat akan terbebas dari perbuatanperbuatan munkar. Mana mungkin orang yang kesehariannya berhubungan dengan Allah, yang merasa kesehariannya diawasi langsung oleh Allah akan berbuat yang keji- keji. Bagi yang shalatnya benar akan memberikan efek pada pelaksananya, yaitu akan bsia berbuat amar ma' ruf nahi munkar (Aziz, 2018).

\section{SIMPULAN}

Dari hasil penelitian dapat disimpulkan bahwa nilai-nilai budaya sekolah yang ada di SD Negeri 5 Mendo Barat yaitu budaya 3S, budaya malu, budaya religius, budaya literasi, budaya menghormati orang yang lebih tua, dan budaya menjaga kebersihan lingkungan. Pelaksanaan pembinaan aktivitas keagamaan di SD Negeri 5 Mendo Barat yang sudah baik, dimana pelaksaan aktivitas keagamaan yang dilakukan sangat disiplin seperti melaksanakan sholat berjemaah,rohis, kultum, tausyiah, dan bersholawat setiap hari jumat. Penanaman pembinaan aktivitas keagamaan di SD Negeri 5 Mendo Barat sejak dini untuk membentuk moral dan karakter baik pada peserta didik. Nilai-nilai dalam budaya sekolah mencakup: kebiasaan hidup, etika, kejujuran, kasih sayang, mencintai belajar, bertanggung jawab, menghormati hukum dan peraturan, menghormati hak orang lain, mencintai pekerjaan, suka menabung, suka bekerja keras, tepat 
waktu. Nilai-nilai mempengaruhi keunggulan sekolah, Karena nilai-nilai mempengaruhi cara bertindak seseorang. Apabila nilai-nilai diimplementasikan oleh keseluruhan orang-orang diorganisasi, maka tentu akan mempengaruhi perilaku organisasi tersebut, termasuk produktivitas organisasi.

\section{REFERENSI}

Al-Warisy, Iskandar. (2012). Pemikiran Islam Ilmiah Menjawab Tantangan Zaman. Surabaya: Yayasan Al-Kahfi

Anwar, C., \& Nuryana, A. (2019). Nilai pendidikan aqidah akhlak dalam surah al-Baqarah ayat 177 dan al-Nisa ayat 36. Atthulab: Islamic Religion Teaching and Learning Journal, 4(2), 144-157. https:// doi.org/10.15575/ath.v4i2.4620

Aziz, M. A. (2018). Abdul aziz. HISBAH: Jurnal Bimbingan Konseling Dan Dakwah Islam.

Busroli, A. (2019). Pendidikan akhlak Ibnu Miskawaih dan Imam al-Ghazali dan relevansinya dengan pendidikan karakter di Indonesia. Atthulab: Islamic Religion Teaching and Learning Journal, 4(2), 236-251. https://doi.org/10.15575/ath.v4i2.5583

Hadziq, A. (2016). Pembelajaran Agama Dan Lingkungan Dalam Kultur Sekolah Alam: Potensi Membumikan Kesadaran Lingkungan Sejak Dini Di Sekolah. Jurnal Tatsqif, 14(1), 1-32. https:/ / doi.org/10.20414/jtq.v14i1.19

Haryanto. (2013). Pendidikan Karakter menurut Ki Hadjar Dewantara. Journal of Chemical Information and Modeling. https://doi.org/10.1017/CBO9781107415324.004

Jamaluddin, D. (2017). Potret Konstruksi Pendidikan Karakter: Kajian pada Lembaga Pendidikan di Jawa Barat. Jurnal Pendidikan UNIGA.

Maryamah, E. (2016). Pengembangan budaya kerja. Tarbawi, 2(02), 207-227. https:/ / doi.org/10.1177/003693307301800103

Muhaimin. (2002). Paradigma Pendidikan Islam. In Livestock Research for Rural Development. https://doi.org/10.1145/2505515.2507827

Parman Komarudin, \& Muhammad Rifqi Hidayat. (2018). PERUSAHAAN SEBAGAI SUBJEK ZAKAT DALAM PERSPEKTIF FIKIH DAN PERATURAN PERUNDANGAN. Al-Iqtishadiyah: Ekonomi Syariah Dan Hukum Ekonomi Syariah.

Priatna, P. (2007). Characteristics of volcanic gas correlated to the eruption activity; Case study in the Merapi Volcano, periods of 1990-1994. Indonesian Journal on Geoscience. https:/ / doi.org/10.17014/ijog.vol2no4.20074

Rosad, W. S. (2017). Penanaman Nilai Religius Melalui Kegiatan Keagamaan Di Mts $\mathrm{Ma}$ ' Arif Nu 1 Ajibarang , Banyumas Jurusan Pendidikan Agama Islam Institut Agama Islam Negeri.

Siregar, F. R. (2017). “ Nilai-Nilai Budaya Sekolah dalam Pembinaan Aktivitas Keagamaan Siswa SD IT Bunayya Padangsidimpuan ." Jurnal Pusat Studi Gender Dan Anak, 1.

Sukardi, I. (2016). Character Education Based on Religious Values: an Islamic Perspective. Ta'dib, 21(1), 41. https://doi.org/10.19109/td.v21i1.744

Surur, A. M. (2018). Upaya Menanamkan Nilai Religius Siswa Di Man Kediri 1 
Muhammad Iqbal Arrosyad, Siti Nur Oktaviani, Harsela Eftia, Nadia Karisma, Bella Meliyana

Kota Kediri Dengan Ekstrakurikuler Keagaman Tahfidz Al-Qur'an. Jurnal Pendidikan Agama Islam, 15(1), 42-51. https://doi.org/10.14421/jpai.2018.151-03

Tarbiyah, Z. F., Email, I., Pendidikan, A., Hasanah, S., Diniyyah, M., \& Hasanah, S. (2016). Pendekatan Terpadu dalam Membentuk Karakter Santri di Pondok Pesantren Sabilul Hasanah Banyuasin III. Intizar, 19(1), 189-204. https://doi.org/10.19109/intizar.v19i1.409 